\title{
Rangifer management controls a climate-sensitive tundra state transition
}

\author{
Kari Anne Bråthen, ${ }^{1,4}$ Virve Tuulia Ravolainen, ${ }^{2}$ Audun Stien, ${ }^{3}$ Torkild TveraA, ${ }^{3}$ and Rolf A. Ims ${ }^{1}$ \\ ${ }^{1}$ Department of Arctic and Marine Biology, UiT-The Arctic University of Norway, N-9037 Tromsø, Norway \\ ${ }^{2}$ Norwegian Polar Institute, Fram Centre, NO-9296 Tromsø, Norway \\ ${ }^{3}$ The Norwegian Institute for Nature Research, Fram Centre, NO-9296 Tromsø, Norway
}

\begin{abstract}
Rangifer (caribou/reindeer) management has been suggested to mitigate the temperature-driven transition of Arctic tundra into a shrubland state, yet how this happens is uncertain. Here we study this much focused ecosystem state transition in riparian areas, where palatable willows (Salix) are dominant tall shrubs and highly responsive to climate change. For the state transition to take place, small life stages must become tall and abundant. Therefore we predicted that the performance of small life stages (potential recruits) of the tall shrubs were instrumental to the focal transition, where Rangifer managed at high population density would keep the small-stage shrubs in a "browse trap" independent of summer temperature. We used a large-scale quasi-experimental study design that included real management units that spanned a wide range of Rangifer population densities and summer temperatures in order to assess the relative importance of these two driving variables. Ground surveys provided data on density and height of the small shrub life stages, while the distributional limit (shrubline) of established shrublands (the tall shrub life stage) was derived from aerial photographs. Where Rangifer densities were above a threshold of approximately 5 animals $/ \mathrm{km}^{2}$, we found, in accordance with the expectation of a "browse trap," that the small life stages of shrubs in grasslands were at low height and low abundance. At Rangifer densities below this threshold, the small life stages of shrubs were taller and more abundant indicating Rangifer were no longer in control of the grassland state. For the established shrubland state, we found that the shrubline was at a $100-$ $\mathrm{m}$ lower elevation in the management units where Rangifer had been browsing in summer as opposed to the migratory ranges with no browsing in summer. In both seasonal ranges, the shrubline increased $100 \mathrm{~m}$ per $1{ }^{\circ} \mathrm{C}$ increment in temperature. Our study supports the proposal that Rangifer management within a sustainable range of animal densities can mitigate the much-focused transition from grassland to shrubland in a warming Arctic.
\end{abstract}

Key words: browse trap; browsing; climate change; life history stage; plant-herbivore interactions; Salix; shrub growth; shrubline; summer temperature.

\section{INTRODUCTION}

Climate warming currently causes changes in the physical and biological characteristics of the Arctic (Bhatt et al. 2010, 2013), with the most conspicuous earth surface change being the shift toward increased shrub abundance in tundra landscapes (Walker 2000, Sturm et al. 2001, Post et al. 2009, Wookey et al. 2009, Myers-Smith et al. 2011a). Increased shrub abundance has the potential to induce positive climate feedback through reduced albedo, increased ground temperatures, and changes in a range of biophysical processes (Chapin et al. 2005, Wookey et al. 2009, Myers-Smith et al. 2011a, Cohen et al. 2013, Pearson et al. 2013, Menard et al. 2014) but see Blok et al. (2010). At the same time, abundant shrubs form habitat that enhances species richness of a range of organism groups such as birds, insects, and vascular plants (Roininen et al. 2005, Ims

Manuscript received 2 March 2017; revised 26 June 2017; accepted 28 July 2017. Corresponding Editor: N. Thompson Hobbs.

${ }^{4}$ E-mail: kari.brathen@uit.no and Henden 2012, Henden et al. 2013, Rich et al. 2013, Sweet et al. 2014, Bråthen and Lortie 2016). However, current predictions on the extent and rate of warminginduced tundra ecosystem state shifts toward shrub dominance are currently hampered by unknown context dependencies (Myers-Smith et al. 2011b, Bernes et al. 2015, Swanson 2015). Here we focus on shrub increase in a particularly climate-sensitive tundra ecosystem and under a particularly influential context that is often subjected to management interventions and large mammalian herbivory in order to progress the understanding of what influences state shifts in the circumpolar tundra.

Shrub increase in tundra ecosystems is strongly linked to climate warming (Forbes et al. 2010, Myers-Smith et al. 2011b, Elmendorf et al. 2012, Pearson et al. 2013, Buntgen et al. 2015). However, Arctic shrubs exhibit considerable intra- and interspecific heterogeneity in their temperature response (Normand et al. 2013, Buntgen et al. 2015), with plant traits such as longevity and size as important determinants. Strong responses to climate warming are most evident among shrub species with an intrinsic capacity to grow tall in habitats with 
high soil moisture (Elmendorf et al. 2012, Myers-Smith et al. 2015), such as Salix in riparian habitats (Tape et al. 2012). Moreover, tall shrub species also provide the strongest climate feedbacks (Kramshøj et al. 2016, Williamson et al. 2016).

Salix shrubs are palatable to many herbivores (Wolf et al. 2007, Christie et al. 2015). Thus, herbivory might be a highly influential moderator to the response of shrubs to climate warming. Experimental studies excluding browsing activities have shown that both small and large herbivores can have strong impacts on shrubs, to the extent that they inhibit shrub increase in tundra ecosystems (e.g., den Herder et al. 2008, Olofsson et al. 2009, Ravolainen et al. 2014). Conclusions from these studies have been based on extensive scales and covering a range of environmental contexts, but with their relevance to herbivore management has being unclear. Still, herbivore management has repeatedly been suggested as a way to mitigate shrub expansion in the circumpolar tundra (Post and Pedersen 2008, Olofsson et al. 2009, Ims and Ehrich 2013, Biuw et al. 2014, Ravolainen et al. 2014, Väisänen et al. 2014).

However, tall shrubs can grow out of the physical foraging range of large herbivores and thereby become invulnerable to their browsing. Hence it is the small life stages within reach of the herbivores, such as saplings and ramets, that are likely to experience decreases in both height and abundance (Christie et al. 2015). Moreover, this decrease is likely to be exponential with

FIG. 1. A conceptual framework predicting how population density of a large herbivore can influence a climate-sensitive state shift from grassland to a shrubland state and in consequence cause an advancing shrubline. The large herbivore density is assumed to be proportional to the browsing pressure on palatable shrubs. (a) In grasslands, large herbivores readily browse small life stages of palatable shrubs (saplings or small ramets) that are within their physical foraging range. The abundance of small stage shrubs (i.e., their heights and/or density) decreases nonlinearly with browsing intensity (cf. Hegland and Rydgren 2016) so that the shrubs are kept in a browse trap independently of summer temperature when the browsing pressure (and animal density) is high. At lower browsing pressures and in a warming climate, the small shrubs will escape the browse trap and grow into a tall life stage. In consequence, shrub increase promoted by climate warming (Elmendorf et al. 2012) is only occurring in the context of a low browsing pressure, i.e., for shrubs that are not in a browse trap. Overall these scenarios give rise to two alternative states, either shifting toward a tall shrub state (shrubland) or continuing in a grassland state (b). In response to increasing temperature, small shrubs can grow taller. Small shrubs can also increase their shoot density, ultimately determining the infilling potential of the shrubs in taking over the grassland. The temperature response finally causes a state shift. (c) A state shift will eventually cause shrublands to expand into higher latitudes and altitudes, and advance the shrubline. Such shrub increase is not possible for small shrubs caught in a browse trap as they are parts of persisting grassland with an arrested shrubline. The framework builds on a conceptual model of shrub increase (cf. Tape et al. 2006, Myers-Smith et al. 2011b) and the concept of the browse trap (cf. Staver and Bond 2014). [Color figure can be viewed at wileyonlinelibrary.com] increasing browsing pressure (Hegland and Rydgren 2016), causing small stages of shrubs to be kept in a "browse trap" at higher herbivore densities (cf. Staver and Bond 2014, Fig. 1a) and from which they are unable escape even under climate warming. In riparian habitats, such herbivore density-dependence can result in bimodal distributions of shrub sizes (small vs. large-stage shrubs, Fig. 1b) and ecosystem states (grassland vs. shrubland, Fig. 1c; cf. House et al. 2003, Pajunen et al. 2010, Tape et al. 2012, Ravolainen et al. 2013), where a climatewarming-induced ecosystem state shift may only occur at low herbivore density (Fig. 1a). Further, altitudinal or latitudinal distribution limits of large stage shrubs, termed shrublines, can only advance under climate potential state shift

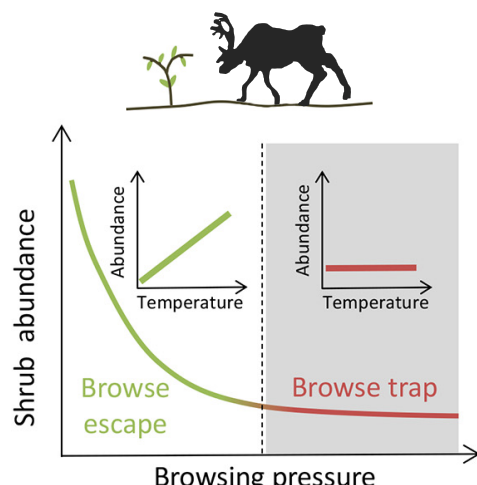

b State shift No state shift
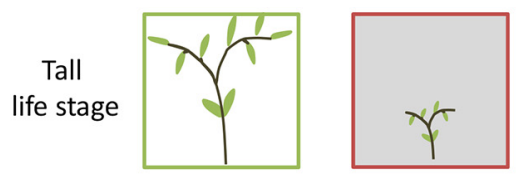

Small life stage
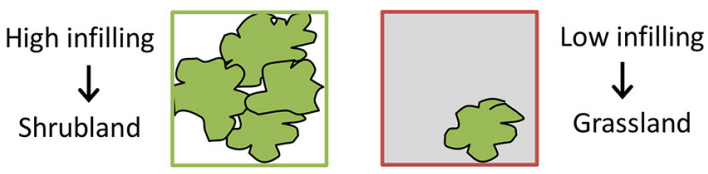

C Shrubland state Grassland state
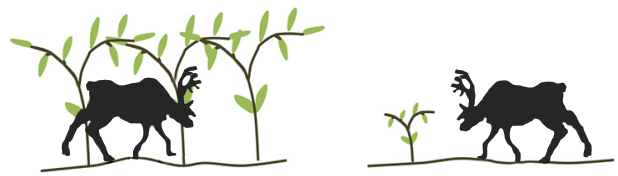

Advancing shrub line
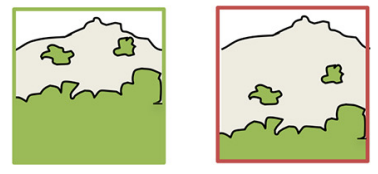

Arrested shrub line 
warming where herbivore density is low (Fig. 1c). Tall shrubs can, however, be very old (Forbes et al. 2010) causing existing shrublands and shrublines to reflect effects of climate warming and herbivore control in the past. Therefore, we advocate focus on small shrub life stages for studying how herbivores may control ongoing and future state shifts, and a focus on tall shrub life stages for understanding past events. The focal large herbivore of the present study, Rangifer tarandus (caribou/ reindeer), is the numerically dominant large herbivore species across the circumpolar tundra, the tundra-forest transition zone and the northern boreal forest. In Eurasia, approximately 2.2 million reindeer are subject to human management (Huntington 2013). Management of both wild and semi-domestic herds is considered important, exerting controls on ecosystems (Ims and Ehrich 2013), such as vegetation state transitions involving shrubs (van der Wal 2006, Post et al. 2009). However, the effects of Rangifer on shrub abundance are variable, most probably because of confounding with ecological context (reviewed in Bernes et al. 2015). Moreover, as exemplified from an alpine ecosystem, shrub growth may not be dependent on relaxed browsing pressure but rather the presence of a favorable hydrology regime (Marshall et al. 2013). Therefore, to assess whether Rangifer management can exert control on the ecosystem state shift scenarios outlined in our conceptual framework (Fig. 1), there is a need to employ study designs that ensure non-confounding between (1) spatial scales, (2) animal densities that are realistic for Rangifer management, (3) temperature gradients, and (4) habitats with an environmental context that allow for life stage transitions in tall shrubs and state transitions of the ecosystem. In the present quasi-experimental study in northernmost Fennoscandia we achieved this by means of field observations and aerial photos of a total of 53 riparian valleys, encompassing a $4^{\circ} \mathrm{C}$ gradient in average summer temperature and Rangifer management units differing between 1.8 and 16.9 animals $/ \mathrm{km}^{2}$ during summer. This allowed us to assess if there is a threshold of managed animal densities above which Rangifer browsing can maintain riparian grasslands within a steady state (cf. Scheffer and Carpenter 2003) and prevent a shift to a shrubland state across a wide range of summer temperatures. Specifically, we estimated the effects of Rangifer density, seasonal range use indicative of past Rangifer density and a gradient in summer temperature on (1) the density and height of small life stages of Salix shrub species in riparian grasslands and (2) the distribution of the shrubline formed by their tall life stages.

\section{Methods}

\section{Study system}

Our study system is within Finnmark, the northernmost, sub-Arctic and low-Arctic part of the Scandinavian Peninsula, spanning $150 \mathrm{~km}$ in latitude and $350 \mathrm{~km}$ in
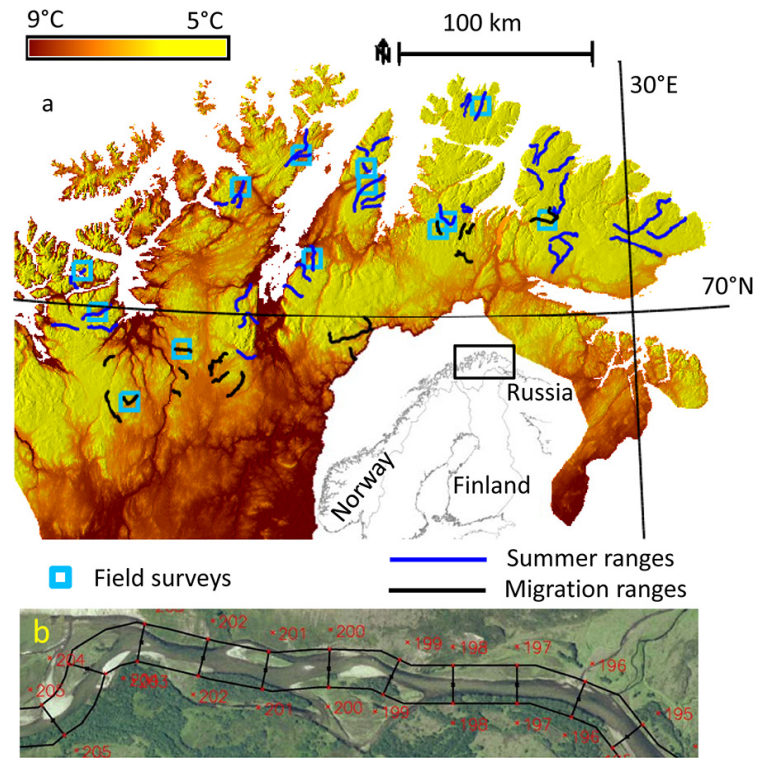

FIG. 2. Study design. (a) Finnmark is partly mountainous, with peaks up to $1,200 \mathrm{~m}$ above sea level (asl) in its western part and $500 \mathrm{~m}$ asl in its eastern part, causing temperature variations across the whole region. River valleys in Rangifer summer ranges (blue lines) or in migration ranges (black lines) were sampled for variables describing the shrubland state (all rivers) and the grassland state (field surveys depicted with blue squares). (b) Data collection of target vegetation states was carried out along sampling lines perpendicular to the river course for each $100 \mathrm{~m}$ down the river. [Color figure can be viewed at wileyonlinelibrary.com]

longitude (Fig. 2). The geographic temperature gradients are very steep in northern Fennoscandia (Jansson et al. 2015) and amount to $4^{\circ} \mathrm{C}$ in average summer temperature (June, July, and August) across the study region. Average precipitation in the summer is 65,54 , and $48 \mathrm{~mm}$ in the west, middle, and east of Finnmark, respectively (Norwegian Meteorological Institute). The region is typically snow covered until early-late June. The study region is characterized by variable bedrock, being mainly gabbro in the west, and slate and sandstone toward the east and interior parts (Geological Survey of Norway). The main vegetation type at lower altitudes (in particular in the western part and inland sections) is sub-Arctic mountain birch forest (Betula pubescens ssp. czerepanovii) and at higher altitudes dwarf shrub tundra (Walker et al. 2005) dominated by Empetrum nigrum, Betula nana, Salix herbacea, and Vaccinium spp. and marshes dominated by Eriophorum spp. and Carex spp. In the most eastern lowArctic section of the study region, the dwarf shrub tundra extends to sea level. Riparian grasslands are common, especially in the larger valleys in the study region, with the presence of Bistorta vivipara and Viola biflora, Avenella flexuosa, Anthoxanthum nipponicum, Deschampsia cespitosa, sedges of Carex spp., and shrubs of Salix spp. (plant names follow the Pan-Arctic Flora; available online). ${ }^{5}$

\footnotetext{
${ }^{5}$ http://nhm2.uio.no/paf/
} 
The Salix shrubs, typically Salix phylicifolia, S. lapponum, S. lanata, and S. hastata and their hybrids (see Ravolainen et al. 2013), have the potential to form 0.5$3 \mathrm{~m}$ tall patches (thickets) that are here defined as a tall life stage. Species of tall Salix shrubs are long lived and highly clonal, with tall-stage stands being several decades to $100 \mathrm{yr}$ old (Forbes et al. 2010), whereas the small life stage can be saplings or ramets. There appears to be no palatability differences between these Salix species (Speed et al. 2013) and, because they often mix in their canopies and hybridize, we have pooled the tall shrub species of Salix in this study.

Rangifer tarandus in Finnmark is semi-domestic and migratory. Their summer pastures are located within management districts at coastal peninsulas, while the winter pastures are located in the inland often close to the Finnish border (Fig. 2a). The areas between the summer and winter pastures are defined as migratory ranges that are visited a few weeks during migration in early spring and late fall, and are mainly snow-covered during these periods. Management rules and an extensive system of fences define the borders between the seasonal ranges as well as between the districts of the summer range. The fences between the seasonal ranges were mostly erected in the 1970s and followed borders that the managers were already accustomed to. However, Rangifer population densities between the management district are not primarily regulated by their resource base in terms of vegetation (Bråthen et al. 2007, Ravolainen et al. 2010). Rather, different national management policies also starting in the 1970s caused Rangifer population densities to vary greatly both in time (Hausner et al. 2011) and spatially across different management units owing to interactions between this policy and internal socioeconomic affairs within and among the herding districts (Hausner et al. 2012). In fact, Næss and Bårdsen (2010) concluded that individual husbandry units' strategies, such as the level of harvesting, have a larger effect on individual husbandry units' population size than does negative density dependence. Accordingly, spatial differences in population size among Rangifer herding units in Finnmark have been persistent over many decades (Bråthen et al. 2007, Appendix S1: Fig. S1). Co-dominant herbivores with Rangifer in Finnmark are voles and lemming (Ims et al. 2007). In addition, moose (Alces alces) and domestic sheep (Ovis aries) are common. Notably, beaver dams that are common in many riparian regions world-wide, and with high impact to Salix growth (Marshall et al. 2013) are not present in our study region.

\section{Study design}

We selected management units of semi-domestic Rangifer to achieve a sample of riparian areas for which summer temperatures and browsing intensities were non-confounded (Appendix S1: Fig. S2) according to a quasi-experimental design (Kerr et al. 2007). The management units spanned the $4^{\circ} \mathrm{C}$ gradient in mean summer temperatures, had contrasting seasonal range use (summer vs. migratory range) and had Rangifer population densities in the summer ranges from 1.8 to 16.9 individu$\mathrm{als} / \mathrm{km}^{2}$ (densities for the years 2009-2011 retrieved from official statistics available online). ${ }^{6}$ We did not attempt to attribute specific Rangifer densities to the migration ranges because the short durations of Rangifer presence in these ranges are likely to inflict a lower browsing pressure for a given Rangifer density. Moreover, the migration ranges are shared to differing and variable degrees between several herds from different summer ranges.

In Finnmark, the geographic coverage of meteorological stations is not large. Thus, to provide a measure of long-term growing-season temperatures, we used modeled estimates downscaled to a $100-\mathrm{m}$ resolution (Pellissier et al. 2013) from WorldClim ("warmest quarter"; Hijmans et al. 2005). The full description of the downscaling procedure can be found in Dullinger et al. (2012). When comparing river valleys we used estimates for the temperature at 200-m altitude as our measure of the river valley temperature.

A total of 23 study units were selected and each represented by a study block, dominated by dwarf shrub tundra and hosting riparian areas (Fig. 2). The size of the study blocks was approximately $30 \times 30 \mathrm{~km}$, but this was modified by coastline patterns, fences separating summer and migration pastures, and the continuous sub-Arctic birch forest that borders the tundra toward the south. In the eastern parts of our study region, the migration ranges are smaller and, in one case, one block included both the migration and summer ranges. Within each block, we selected three river valleys that were either in a summer or in a migration range, and that ascended from either the sea level or from the birch forest line. We selected the largest rivers and/or the ones running in gently sloping terrain above the treeline in order to target rivers that most likely included riparian plains with sediment accumulation, as these conditions provide optimal habitat for the growth of tall Salix shrubs (Pajunen et al. 2010, Ravolainen et al. 2014). A few blocks had less than three river valleys available, in which case, we included all.

Within the river valleys, we established sampling lines along which we sampled both field measurements of the abundance of small-stage shrubs in grasslands and mapped the presence of tall shrubs from aerial photographs (Sturm et al. 2001, Lillesand et al. 2004). We made points along the river valley at $100-\mathrm{m}$ intervals with each point situated in the middle of the river channel (Fig. 2b). The first point was placed well below the forest line, or at sea level in the mouth of the river in areas with no birch forest. The last point was placed in the highalpine vegetation zone where vegetation cover was no longer continuous, or at the source of the watercourse. At each point, a 200-m sampling line was drawn perpendicular to each side of the river (Fig. 2b). These lines served

\footnotetext{
${ }^{6}$ www.landbruksdirektoratet.no
} 
as sampling units for the field measurements and for the analyses of the aerial photographs. In the field, the sampling lines were found using their GPS coordinates.

In sum, the study design admitted sampling of data on shrubs along a range of river valleys, each several kilometers long and including a range of potentially influential abiotic and biotic contexts. Average estimates of both small and tall shrub stages per river valley then provided us with robust response estimates to the specific effects of Rangifer density and temperature.

\section{Measurements of shrub stages}

Presence of tall-stage shrubs (i.e., 0.5-3.0 m tall thickets) was mapped using high-resolution aerial photographs in all river valleys (53 valleys in 23 blocks), whereas measures of small-stage shrubs were recorded by means of field surveys in a subsample of river valleys and blocks (13 blocks with 1 river valley each). The tallstage shrub mapping was used to assess the shrubline per river valley, whereas the small-stage shrub measurements were used to assess growth of the small-stage shrubs into tall shrub stages, averaged per river valley.

In the field surveys, we measured the small-stage shrubs in the riparian grasslands during late July and early August in 2010 (Fig. 2a). Field sampling only included areas that had a minimum distance of $500 \mathrm{~m}$ to human-made constructions (huts, roads). Solitary birch trees were accepted in the field sampling areas but areas including forest (birch $>3 \mathrm{~m}$, less than $30 \mathrm{~m}$ between trees) were excluded.

The sampling lines were first surveyed to get an overview of grassland, tall shrub patches, shrubland, and shrub height within each of the selected river valleys. This initial survey of each river valley also provided data suitable for validation of the aerial photograph analyses (Appendix S1: Fig. S3). For a sampling line to be included in more detailed vegetation analyses, it had to cross grassland or tall shrub patches on river banks. Moreover, within the first $50 \mathrm{~m}$ of the riverbed, the line had to have at least one $10-\mathrm{m}$ segment on level ground with at least two-thirds coverage with grassland vegetation. The final vegetation analysis area was distributed among the sampling lines to include both an upper and lower part of the river valleys. Where several lines were suitable, a random draw was used to select between nearby lines. Sampling lines on stony or gravelly areas and on mire were excluded.

As the vegetation analysis started at the riverbank or at the edge of a tall shrub patch if it occupied the riverbank, sampling line lengths differed. Along the sampling line $10 \mathrm{~m}$ long segments were established using a measuring tape. Within each segment a $1 \mathrm{~m}$ wide strip-transect was surveyed by holding a $1 \mathrm{~m}$ long stick perpendicular to the ribbon while walking.

For a measurement of small shrub density, we counted the number of stems per segment that appeared to be either a ramet or a sapling. We did not dig into the soil to determine if ramets were connected belowground, and counts refer to the number of small shrubs that were not obviously branching from each other. When it was possible to judge without removing soil that several ramets belonged to the same individual, these were counted as one small shrub.

For a measurement of the size of the small-stage shrubs, the height and shoot sum of the first small-stage shrub at the left side of the tape was measured in every segment. If no small-stage shrub was found then the right side of the tape was checked, and if still no small shrub was found, we searched within an expanded striptransect up to $3 \mathrm{~m}$ wid.

For each selected small-stage shrub, we measured the length of the stem, which is used as a primary response variable. Because small shrubs were more or less upright, this is an approximation of height. We also measured the length of all branches longer than $2 \mathrm{~cm}$ to the accuracy of $1 \mathrm{~cm}$. Then we calculated the average total shoot sum as the sum of the stem length and the lengths of all branches. Small-stage shrub length was strongly correlated to shoot sum (Appendix S1: Fig. S4), and hence we subsequently used the stem length variable in the analyses. If the starting point of a sampling line was a tall shrub patch, we recorded its height $( \pm 5 \mathrm{~cm})$ using a ruler.

Using high-resolution aerial photographs from all selected river valleys $(n=58)$ we recorded the distribution of stands of Salix shrubs (Fig. 2). The presence or absence of tall Salix shrubs and/or birch trees along each perpendicular line was assessed by visual inspection of the aerial photographs. The probability of classifying a line as being populated by tall shrubs (0.5-3.0 m height) increased from $50 \%$ when the shrubs along the line were $65 \mathrm{~cm}$ tall to $95 \%$ when shrubs were $130 \mathrm{~cm}$ tall (logistic regression equation $\operatorname{logit}(p)=-2.95+0.046 \times$ shrub height). This imply that mainly tall shrub life stages could be detected using the aerial photographs, while small shrub life stages become indistinguishable from background vegetation in these photographs. Tall shrubs were in general found at higher altitudes than birch trees. As it was not possible to distinguish shrubs within lower parts of some river sections with dense birch forests, tall shrubs were recorded only above the birch forest. The presence-absence data on tall Salix shrubs were used to estimate the altitudinal distribution limit (i.e., the shrubline) within each of the river valleys.

\section{Statistical analysis}

We analyzed the data fitting generalized linear mixed models in $\mathrm{R}$ version 3.0.2 ( $\mathrm{R}$ Core Team 2013).

The field survey generated data from replicated sections ( $n=525)$ within sampling lines $(n=152)$ of the river valleys. To account for dependencies in the observations within sampling lines we included sampling line nested within river valley as a random factor in the analyses. We used the count of ramets and/or saplings within the 10-m sampling segments as the response variable in the analysis 
of small-stage shrub densities. To account for counts from sampling lines of variable length, and to obtain density estimates at the square meter scale, we included $\log$ (sampling line length) as an offset variable in regression models. The residual distribution of the small shrub counts was highly overdispersed. We therefore fitted models assuming a negative binomial distribution and a log link function using the function glmmadmb in the package glmmADMB for R (Bolker et al. 2012). First, we fitted a generalized mixed model with Rangifer density (in the summer ranges) and average summer temperature at $200 \mathrm{~m}$ above sea level as continuous fixed-effect predictor variables, and seasonal range use (summer vs. migration) as categorical fixed effect predictor variables. Plots of the data suggested that the effect of Rangifer densities within the summer ranges was nonlinear with an upper limit to average small shrub densities at low Rangifer densities and a lower limit to average small shrub densities at high Rangifer densities. We therefore estimated the average small shrub density for each river valley using a generalized mixed model with river valley as a fixed factor and sampling line as random effect. To these river specific estimates of small shrub densities from the summer ranges we fitted the following four parameter logistic model: $\log$ (average small shrub density) $=\beta_{1}+\left(\beta_{2}-\beta_{1}\right) /(1+\exp$ $\left(\left(\beta_{3}-\right.\right.$ Rangifer density $\left.\left.) / \beta_{4}\right)\right)$, with $\beta_{i}$ being parameters estimated by the data. In this model, $\beta_{1}$ is the asymptotic $\log$ (small shrub density) as Rangifer density approaches zero, $\beta_{2}$ is the asymptotic $\log$ as Rangifer density approaches infinity, $\beta_{3}$ is the Rangifer density at the inflection point, and $\beta_{4}$ is a slope parameter. The model was fitted using weighted least squares, with weights given by the inverse of the variance of the river specific average small shrub density estimates.

The height of the small-stage shrub was analyzed in linear mixed models with stem length as the response variable. Seasonal range, reindeer density, and average summer temperature were fitted as fixed effect predictor variables. Again, plots of the data suggested that the effect of Rangifer densities within the summer ranges was nonlinear. We therefore proceeded with first estimating the average small-stage shrub height using a linear mixed model with river as a fixed factor and sampling line as random effect, and second, fitted a nonlinear function to these river specific estimates from the summer ranges. The data did not show strong support for an upper limit to average small-stage shrub height at low reindeer densities, and we therefore used the following three-parameter nonlinear model: small-stage shrub height $=\beta_{1}+\left(\beta_{2}-\beta_{1}\right) \times \exp \left(-\exp \left(\beta_{3}\right) \times\right.$ Rangifer density), with $\beta_{\mathrm{i}}$ being parameters estimated by the data. In this model, $\beta_{1}$ is the asymptotic small-stage shrub height as Rangifer density approaches infinity, $\beta_{2}$ is the predicted small-stage shrub height at a Rangifer density of zero, and $\beta_{3}$ is a slope parameter. The model was fitted using weighted least squares, with weights given by the inverse of the variance of the river-specific average small-stage shrub height estimates.
The altitudinal shrubline was estimated from the presence/absence data of the tall shrub stage from the aerial photographs by fitting a logistic function of form: probability of presence $=P=1 /\left(1+\exp \left(\left(\beta_{1}-\right.\right.\right.$ altitude $)$ $\left.\beta_{2}\right)$ ), where $\beta_{1}$ is the altitude at $P=0.5$ and $\beta_{2}$ is the estimated slope for the decrease in probability of presence with altitude, to the resulting binary data from each river valley. The model was fitted to each river valley included in the study, assuming a binomial error distribution. In subsequent analyses, we used the estimates of $\beta_{1}$ as our measures of the shrubline. For some river valleys furthest to the north and east of the study area, neither birch nor tall shrubs were present along the river, and the shrubline was set to $0 \mathrm{~m}$.

We used the estimates of $\beta_{1}$ as the response variable in the analysis of the spatial variation in the shrubline, and included the design variable "study block" as a random factor in linear mixed models. As above, the average summer temperature at $200 \mathrm{~m}$ above sea level for each river valley, and Rangifer seasonal range use (summer vs. migration) were fitted as continuous and categorical fixed effects, respectively. In addition, we investigated the potential effect of the logarithm of the Rangifer density on the shrubline in the summer ranges. For model selection, we fitted the models using maximum likelihood and evaluated nested models using likelihood ratio tests. The final statistical model for the spatial variation in the shrubline included the additive fixed effects of reindeer seasonal range use (summer or migration range) and temperature. There was no evidence for any interaction (i.e., different slope estimates for the temperature response) between seasonal range use and temperature.

\section{Results}

\section{Small shrub stage}

Both average height and density of small-stage shrubs were nonlinearly related to reindeer density in the summer pastures (Fig. 3a, b) and agreed with our expectation of a browse trap (Fig. 1). That is, over the range of 3-6 reindeer $/ \mathrm{km}^{2}$ the density of small shrubs decreased by a factor of about 20 and their heights were on average halved. The browse trap was indicated at higher reindeer densities (approximately $>5-6$ reindeer $/ \mathrm{km}^{2}$ ), as there was no further change in shrub density or height. In the migratory ranges, where reindeer are not browsing in the summer, the small shrubs had the same range in heights and densities as in the summer pastures with the lowest reindeer density (Fig. 3). Notably, the height and density of the small shrubs were not related to the temperature differences among the river valleys (Table 1; Appendix S1: Fig. S5). Small-stage shrubs were frequently present independent of altitudinal deviance from the shrubline (Fig. 4), indicating a potential for transition to the tall-shrub stage and shrubland in all the surveyed river valleys. 

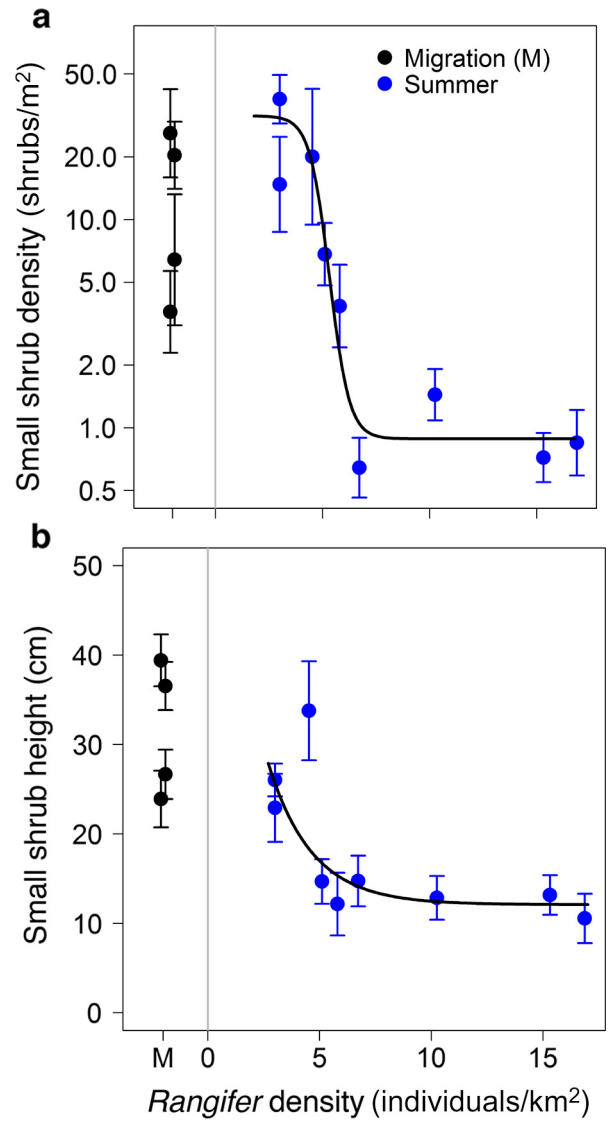

FIG. 3. (a) Small shrub density and (b) small shrub height (means $\pm \mathrm{SE}$ ) estimated for river valleys in Rangifer summer ranges $(n=9)$ and migration ranges $(\mathrm{M}, n=4)$ included in the field surveys (light blue polygons in Fig. 2a). Nonlinear regression lines indicate the relationship between small shrub performance and Rangifer density in the summer ranges (regression equations for (a) small shrub density in summer ranges $=\beta_{1}+\left(\beta_{2}-\beta_{1}\right) /\left(1+\exp \left(\left(\beta_{3}-\right.\right.\right.$ Rangifer density $\left.\left.) / \beta_{4}\right)\right)$, with $\beta_{1}=3.45, \mathrm{SE}=0.36, \beta_{2}=-0.12, \mathrm{SE}=0.23, \beta_{3}=5.32$, $\mathrm{SE}=0.26, \beta_{4}=0.46, \mathrm{SE}=0.27$; and for (b) small shrub height in summer ranges $=\beta_{1}+\left(\beta_{2}-\beta_{1}\right) \times \exp \left(-\exp \left(\beta_{3}\right) \times\right.$ Rangifer density), with $\beta_{1}=12.1, \quad \mathrm{SE}=2.0, \quad \beta_{2}=74.7, \quad \mathrm{SE}=56.4$, $\beta_{3}=-0.67, \mathrm{SE}=0.59$ ). [Color figure can be viewed at wileyonlinelibrary.com]

\section{Tall shrub stage}

The altitudinal shrubline increased with increasing mean summer temperature and was as expected consistently lower where Rangifer browse in summer compared to migration areas. The shrubline increased linearly on average by $101 \mathrm{~m}(95 \% \mathrm{CI}=65-137)$ in altitude for each $1^{\circ} \mathrm{C}$ higher mean summer temperature, causing a major transition across the $4^{\circ} \mathrm{C}$ temperature gradient of the study system (Fig. 5). The higher browsing impact in the summer ranges amounted to an estimated altitudinal shrub line that was on average $104 \mathrm{~m}(95 \% \mathrm{CI}=40-168)$ lower altitude than in the migration ranges. The effect of Rangifer density on the shrubline within the summer ranges was negative but not statistically significant (estimated slope $=-3.6$, $95 \% \mathrm{CI}=-12.4-5.2$ ).

\section{Discussion}

We found Rangifer management to represent an external mechanism (sensu Scheffer and Carpenter 2003) that maintains riparian grasslands in a steady state across a $4^{\circ} \mathrm{C}$ gradient in summer temperature. Rangifer populations managed at high densities appear to prevent climate warming from pushing tundra into a shrubland state because the small life stages of tall shrubs are kept in a "browse trap" (Staver and Bond 2014). In turn, the browse trap prevents altitudinal and latitudinal shrub lines from advancing, corresponding with the scenario depicted in our conceptual framework (Fig. 1). Specifically, we found that the critical browsing pressure exerted by Rangifer was achieved at herd densities above approximately 5 animals $/ \mathrm{km}^{2}$ and acted independently of summer temperature. This density threshold was still within the lower range of Rangifer densities in Finnmark (ranging from 1.8 to 16.9 animals $/ \mathrm{km}^{2}$ during the study period). In management units with Rangifer densities below the threshold, we found small life stages of tall shrub species to increase in size and density, indicating Rangifer managed at low densities cannot control the shift from grassland to shrubland in a warmer climate.

TABLE 1. Parameter estimates and AIC values for different models for the effect of being in a summer range (in contrast to the migration range), Rangifer density, and average summer temperature on the density and the height of small-stage shrubs.

\begin{tabular}{|c|c|c|c|c|c|}
\hline Model & Intercept & Summer range & Rangifer density & Temperature & $\mathrm{AIC}$ \\
\hline \multicolumn{6}{|c|}{ Density of small-stage shrubs } \\
\hline 1 & $2.84(3.49)$ & $-1.21(0.84)$ & & $-0.06(0.48)$ & 4,042 \\
\hline 2 & $2.46(0.48)$ & $0.69(0.75)$ & $-0.24(0.06)$ & & 4,032 \\
\hline 3 & $-1.45(2.47)$ & $1.30(0.79)$ & $-0.28(0.06)$ & $0.55(0.34)$ & 4,032 \\
\hline \multicolumn{6}{|c|}{ Height of small-stage shrubs } \\
\hline 1 & $29.6(17.7)$ & $-14.8(4.5)$ & & $0.4(2.8)$ & 2,718 \\
\hline 2 & $13.3(7.7)$ & $19.3(13.6)$ & $-8.1(3.1)$ & & 2,711 \\
\hline 3 & $1.1(19.9)$ & $21.8(14.9)$ & $-8.8(3.5)$ & $1.7(2.5)$ & 2,712 \\
\hline
\end{tabular}

Notes: The estimates were obtained using a negative binomial GLMM with a log link function (density) and a linear mixed effects models and log transformed Rangifer density (height), both with sampling line nested within river valley as random effects. Parameter estimates that differ significantly from zero $(P<0.05)$ are shown in boldface type. 


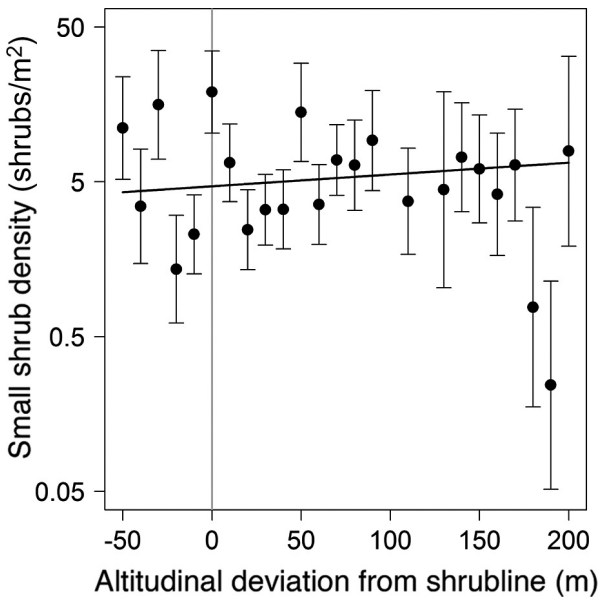

FIG. 4. Small-stage shrub densities (mean $\pm \mathrm{SE}$ ) in riparian grasslands plotted against the deviance between the altitude of sampling lines along river valleys and the estimated shrubline. The small-stage shrub density was modelled using a log linear model. The regression line is given by $y=\exp \left(\beta_{0}+\beta_{1} \times x\right)$, with $\beta_{0}=1.54(95 \% \mathrm{CI}=[0.70,2.38])$ and $\beta_{1}=0.0018(95 \%$ $\mathrm{CI}=[-0.0040,0.0076])$.

Thus riparian tundra may occur in two alternative states, or attractors, in a warming climate (sensu Scheffer and Carpenter 2003) in response to variation in managed Rangifer densities.

We found small-stage shrubs to be present across the entire temperature gradient reflecting that our study region is currently situated within the climate envelope

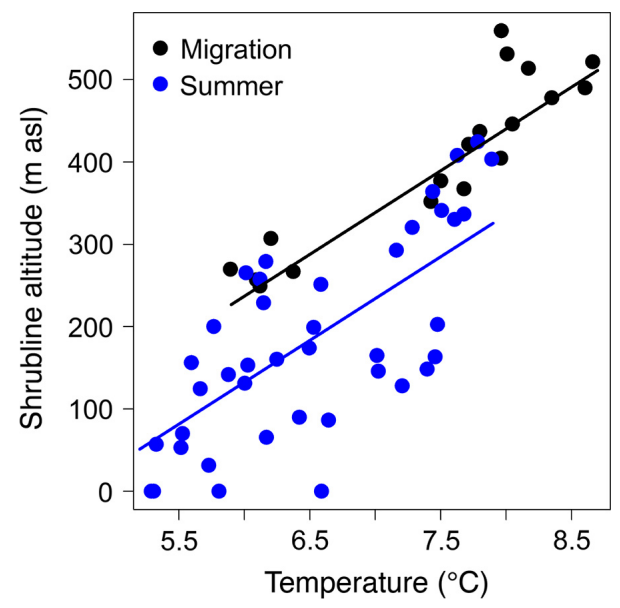

FIG. 5. The altitudinal shrubline of the shrubland state was estimated for each sampled river valley (points), from records of stands of tall willow (Salix) shrubs along the sampling lines using aerial photographs. The regression lines indicate the average pattern of variation in the shrubline with temperature for the Rangifer summer ( $n=40$, blue line and points) and migration ranges $(n=18$, black line and points) (shrubline $=-372$ $[ \pm 134]+102[ \pm 18] \times$ temperature $-104[ \pm 32] \times$ summer range, with $\pm \mathrm{SE}$ of estimates given in brackets). [Color figure can be viewed at wileyonlinelibrary.com] for Salix species that have the potential to shift to a tall stage (Walker et al. 2005). Within this range of $5^{\circ}-9^{\circ} \mathrm{C}$ in summer temperatures, we found Rangifer to control two distinct ways for small shrubs to increase, i.e., in small shrub density and height, indicating the browse trap can be more than just a control of height (cf. Staver and Bond 2014). In this respect, our results contrast with a recent study based on a mass-balance food-web modeling approach, which concluded that herbivores do not regulate low-Arctic tundra vegetation (Legagneux et al. 2014). For instance, if regulation is specific to the small life stage of tall shrubs, herbivores can regulate a vegetation state by consuming only a small proportion of the total shrub biomass production, indicating that massbalance approaches will be insensitive to such regulation. Indeed, for a state variable to be a leading determinant of a state change, it is beneficial if it is involved in the temporal dynamics of the state transition (Bestelmeyer et al. 2011). In our study system, the small life stages of the tall shrubs can be considered to be such leading determinants of the focal ecosystem state shift, because the dynamics of these life stages are sensitive to both herbivory and temperature.

Stands of tall shrubs can be old clonal structures (Forbes et al. 2010). Thus, the suppressed altitudinal limit of the tall shrub state in the Rangifer summer ranges relative to the migration ranges indicates that there have been browse traps during the last decades across all the management units of the summer ranges. This is likely for two reasons. First, the geographic gradients in summer temperatures as well as the contrast in browsing pressure between migration and summer ranges (as determined by the migration behavior of Rangifer) are likely to have persisted for centuries (Vorren 1962). Second, since 1950 Rangifer densities have fluctuated below and above 5 animals $/ \mathrm{km}^{2}$ within several management units of Finnmark (Tveraa et al. 2007, González et al. 2010), causing temporal variation in the potential for shrubs to increase in abundance or be arrested in browse traps. Still, the impacts of both climate warming and Rangifer management were less intense in the past, when Rangifer numbers in the study region were generally lower (González et al. 2010) and climate was colder (Førland et al. 2009). Hence, the current distribution of tall shrubs (i.e., the altitudinal shrubline) is likely to reflect process rates at a time when the transition from grassland to shrubland was slower. With the ongoing increase in temperatures there is reason to expect that processes are speeding up and that even a few years of relaxed summer browsing pressure in the future may trigger a rapid shift from riparian grasslands to shrublands (Marshall et al. 2014).

While our study suggests that Rangifer densities above 5 animals $/ \mathrm{km}^{2}$ keep grasslands in a persistent browse trap over a wide range of temperatures, there are alternative trajectories for how the grassland state may be a common state in riparian areas. First, there is a high 
uncertainty for the future role of herbivores in the Arctic because the herbivores are themselves directly impacted by climate change (Ims and Fuglei 2005, Vors and Boyce 2009). Rangifer population densities are expected to decrease due to climate warming and may gradually be replaced by even more effective browsers (Ims and Ehrich 2013). Indeed, more specialized ungulate browsers (i.e., moose and red deer) are already increasing within the range of Rangifer in Fennoscandia (Austrheim et al. 2011). Under a scenario of either continuously high Rangifer densities above 5 animals $/ \mathrm{km}^{2}$ (that already seems to be the case within certain management units of Finnmark; Bernes et al. 2015) or high densities of other ungulate browsers, we might expect grasslands to be in a persistent browse trap. Second, grass cover promoting fire is a mechanism for stability of the grassland state for several grassland systems in the world (Ratajczak et al. 2014) and may become more frequent in the future also in the Arctic (Ims and Ehrich 2013). Third, there may be other environmental constraints that limit the growth response of small lifestages of Salix to changes in browsing pressure. For instance, Salix growth may be limited by the local hydrological regime (Marshall et al. 2013, 2014), with significant impact on the ability of Salix to respond to a decrease in browsing pressure. However, whereas such environmental constraints can be common and of local importance, they were not confounded with Rangifer densities across the larger scale of our study region (see also Bråthen et al. 2007, Bråthen and Ravolainen 2015).

A state shift to shrubland will affect tundra ecosystem functioning (Andersen et al. 2009) beyond the climate feedbacks. For instance, tundra shrublands are habitat to numerous species of birds (Roininen et al. 2005, Ims and Henden 2012, Henden et al. 2013), insects (Rich et al. 2013) and a diversity of other plants (at least when below $40 \mathrm{~cm}$; Bråthen and Lortie 2016). Also, whereas Rangifer management can prevent the state shift from grassland to shrubland from occurring, high Rangifer densities affect herd productivity (Tveraa et al. 2007), predation rate (Tveraa et al. 2014), may deplete lichen resources in the winter ranges (Tømmervik et al. 2009, Bernes et al. 2015) and reduce the abundance of forbs in the summer ranges (Bråthen et al. 2007, Bernes et al. 2015). Therefore, it seems Rangifer management needs to strike a balance between the perceived positive and negative impacts of Rangifer densities. In particular, management needs to consider enriching the ecosystem functioning of riparian tundra by having the two states coexist, as well as considering the associated climate feedbacks and the livelihood of local resource-dependent people (Huntington 2013, Ims and Ehrich 2013).

Currently there are predictions of a $50 \%$ increase in the shrub state across the circumpolar region (Pearson et al. 2013). These predictions are based on abiotic drivers alone. Our study shows that Rangifer management in the warmest region of the Arctic (Callaghan et al. 2004) currently can control this ecosystem transition, indicating the impact of large herbivores may significantly reduce the magnitude of these predictions. Notably, our study region holds among the highest densities of Rangifer in the world (Bernes et al. 2015), and the moderate Rangifer densities at which we found the browse trap to act are still relatively high in a circumpolar comparison. Furthermore, the capacity of herbivores to prevent shrub increase is dependent on the palatability of the shrubs, where for instance nonpalatable tall shrubs such as species of Alnus gain abundance even in areas of higher browsing pressures (Christie et al. 2015). Such non-palatable tall shrubs were not present in our study system (Pan-Arctic Flora; see footnote 5 ). Nevertheless, by targeting riparian tundra that contain high quality habitats, and encompassing a wide range in animal densities and thus browsing pressure, we expect our results to be of relevance to other circumpolar regions where Rangifer are managed through herding or hunting (Huntington 2013). Being the first study to demonstrate how management can control a climate-sensitive ecosystem state shift in Arctic tundra (cf. Ims and Ehrich 2013), we also provide a case for how appropriate quasi-experimental designs can be applied in studies in other terrestrial biomes with the purpose of assessing the relative importance of climate change and managed large herbivores as drivers of ecosystem state shifts.

\section{ACKNOWLEDGMENTS}

Virve Ravolainen and Kari Anne Bråthen are joint first authors. We thank Alena Gbelcova, Karen Lone, Gunhild Skogstad, Leif-Einar Støvern, Pavel Šurán, Vegar Nilsen Trasti, and Geir Vie for assistance in the field, the Reindeer Police for field accommodation, and Manuel Ballesteros for help with processing of aerial photographs. We thank Lennart Nilsen, Loïc Pellisier, and Christoph Randin for help with the temperature data, Tove Midtun for illustrations, Jennifer Stien for language revision, and colleagues in the project "EcoFinn" for discussions. The study was financed by the Norwegian Research Council grant to the project "EcoFinn" and is a contribution from COAT (Climate-ecological Observatory for Arctic Tundra; http://www.coat.no/).

\section{Literature Cited}

Andersen, T., J. Carstensen, E. Hernandez-Garcia, and C. M. Duarte. 2009. Ecological thresholds and regime shifts: approaches to identification. Trends in Ecology and Evolution 24:49-57.

Austrheim, G., E. J. Solberg, and A. Mysterud. 2011. Spatiotemporal variation in large herbivore pressure in Norway during 1949-1999: has decreased grazing by livestock been countered by increased browsing by cervids? Wildlife Biology 17:286-298.

Bernes, C., K. A. Bråthen, B. C. Forbes, J. D. Speed, and J. Moen. 2015. What are the impacts of reindeer/caribou (Rangifer tarandus L.) on arctic and alpine vegetation? A systematic review. Environmental Evidence 4:1-26. 
Bestelmeyer, B. T., et al. 2011. Analysis of abrupt transitions in ecological systems. Ecosphere 2:1-26.

Bhatt, U. S., et al. 2010. Circumpolar Arctic tundra vegetation change is linked to sea ice decline. Earth Interactions 14:4229-4254.

Bhatt, U., D. Walker, M. Raynolds, P. Bieniek, H. Epstein, J. Comiso, J. Pinzon, C. Tucker, and I. Polyakov. 2013. Recent declines in warming and vegetation greening trends over panArctic tundra. Remote Sensing 5:4229.

Biuw, M., et al. 2014. Long-term impacts of contrasting management of large ungulates in the Arctic tundra-forest ecotone: ecosystem structure and climate feedback. Ecosystems 17:890-905.

Blok, D., M. M. P. D. Heijmans, G. Schaepman-Strub, A. V. Kononov, T. C. Maximov, and F. Berendse. 2010. Shrub expansion may reduce summer permafrost thaw in Siberian tundra. Global Change Biology 16:1296-1305.

Bolker, B., H. Skaug, A. Magnusson, and A. Nielsen. 2012. Getting started with the glmmADMB package. glmmadmb.rforge.r-project.org/glmmADMB.pdf

Bråthen, K. A., and C. Lortie. 2016. A portfolio effect of shrub canopy height on species richness in both stressful and competitive environments. Functional Ecology 30:60-69.

Bråthen, K. A., and V. Ravolainen. 2015. Niche construction by growth forms is as strong a predictor of species diversity as environmental gradients. Journal of Ecology 103:701713.

Bråthen, K. A., R. A. Ims, N. G. Yoccoz, P. Fauchald, T. Tveraa, and V. Hausner. 2007. Induced shift in ecosystem productivity? Extensive scale effects of abundant large herbivores. Ecosystems 10:773-789.

Buntgen, U., L. Hellmann, W. Tegel, S. Normand, I. MyersSmith, A. V. Kirdyanov, D. Nievergelt, and F. H. Schweingruber. 2015. Temperature-induced recruitment pulses of Arctic dwarf shrub communities. Journal of Ecology 103: 489-501.

Callaghan, T., et al. 2004. Synthesis of impacts in four arctic subregions. Ambio 33:469-473.

Chapin, F. S., et al. 2005. Role of land-surface changes in Arctic summer warming. Science 310:657-660.

Christie, K. S., J. P. Bryant, L. Gough, V. T. Ravolainen, R. W. Ruess, and K. D. Tape. 2015. The role of vertebrate herbivores in regulating shrub expansion in the Arctic: a synthesis. BioScience 65:1123-1133.

Cohen, J., J. Pulliainen, C. B. Menard, B. Johansen, L. Oksanen, K. Luojus, and J. Ikonen. 2013. Effect of reindeer grazing on snowmelt, albedo and energy balance based on satellite data analyses. Remote Sensing of Environment 135:107-117.

Dullinger, S., et al. 2012. Extinction debt of high-mountain plants under twenty-first-century climate change. Nature Climate Change 2:619-622.

Elmendorf, S. C., et al. 2012. Global assessment of experimental climate warming on tundra vegetation: heterogeneity over space and time. Ecology Letters 15:164-175.

Forbes, B. C., M. M. Fauria, and P. Zetterberg. 2010. Russian Arctic warming and 'greening' are closely tracked by tundra shrub willows. Global Change Biology 16:1542-1554.

Førland, E. J., R. E. Benestad, F. Flatøy, I. Hanssen-Bauer, J. E. Haugen, K. Isaksen, A. Sorteberg, and B. Ådlandsvik. 2009. Climate development in North Norway and the Svalbard region during 1900-2100. Norwegian Polar Institute, Tromsø, Norway.

González, V. T., K. A. Bråthen, V. T. Ravolainen, M. Iversen, and S. B. Hagen. 2010. Large-scale grazing history effects on Arctic-alpine germinable seed banks. Plant Ecology 207: 321-331.
Hausner, V. H., P. Fauchald, T. Tveraa, E. Pedersen, J. L. Jernsletten, B. Ulvevadet, R. A. Ims, N. G. Yoccoz, and K. A. Bråthen. 2011. The ghost of development past: the impact of economic security policies on Saami pastoral ecosystems. Ecology and Society 16:4.

Hausner, V. H., P. Fauchald, and J. L. Jernsletten. 2012. Community-based management: under what conditions do Sami pastoralists manage pastures sustainably? PLoS ONE 7: e51187.

Hegland, S. J., and K. Rydgren. 2016. Eaten but not always beaten: winners and losers along a red deer herbivory gradient in boreal forest. Journal of Vegetation Science 27: 111-122.

Henden, J. A., N. G. Yoccoz, R. A. Ims, and K. Langeland. 2013. How spatial variation in areal extent and configuration of labile vegetation states affect the riparian bird community in Arctic tundra. PLoS ONE 8:e63312.

den Herder, M., R. Virtanen, and H. Roininen. 2008. Reindeer herbivory reduces willow growth and grouse forage in a forest-tundra ecotone. Basic and Applied Ecology 9:324-331.

Hijmans, R. J., S. E. Cameron, J. L. Parra, P. G. Jones, and A. Jarvis. 2005. Very high resolution interpolated climate surfaces for global land areas. International Journal of Climatology 25:1965-1978.

House, J. I., S. Archer, D. D. Breshears, and R. J. Scholes. 2003. Conundrums in mixed woody-herbaceous plant systems. Journal of Biogeography 30:1763-1777.

Huntington, H. 2013. Provisioning and cultural services. Pages 593-626 in H. Meltofte, editor. Arctic biodiversity assessment. Status and trends in Arctic biodiversity. Conservation of Arctic Flora and Fauna, Akureyri, Iceland.

Ims, R. A., and D. Ehrich. 2013. Terrestrial ecosystems. Pages 384-440 in H. Meltofte, editor. Arctic biodiversity assessment. Status and trends in Arctic biodiversity. Conservation of Arctic Flora and Fauna, Akureyri, Iceland.

Ims, R. A., and E. Fuglei. 2005. Trophic interaction cycles in tundra ecosystems and the impact of climate change. BioScience 55:311-322.

Ims, R. A., and J. A. Henden. 2012. Collapse of an arctic bird community resulting from ungulate-induced loss of erect shrubs. Biological Conservation 149:2-5.

Ims, R. A., N. G. Yoccoz, K. A. Bråthen, P. Fauchald, T. Tveraa, and V. Hausner. 2007. Can reindeer overabundance cause a trophic cascade? Ecosystems 10:607-622.

Jansson, R., et al. 2015. Future changes in the supply of goods and services from natural ecosystems: prospects for the European north. Ecology and Society 20:32.

Kerr, J. T., H. M. Kharouba, and D. J. Currie. 2007. The macroecological contribution to global change solutions. Science 316:1581-1584

Kramshøj, M., I. Vedel-Petersen, M. Schollert, A. Rinnan, J. Nymand, H. Ro-Poulsen, and R. Rinnan. 2016. Large increases in Arctic biogenic volatile emissions are a direct effect of warming. Nature Geoscience 9:349-352.

Legagneux, P., et al. 2014. Arctic ecosystem structure and functioning shaped by climate and herbivore body size. Nature Climate Change 4:379-383.

Lillesand, T. M., R. W. Kiefer, and J. W. Chipman. 2004. Remote sensing and image interpretation. Fifth edition. Wiley, New York, New York, USA.

Marshall, K. N., N. T. Hobbs, and D. J. Cooper. 2013. Stream hydrology limits recovery of riparian ecosystems after wolf reintroduction. Proceedings of the Royal Society B 280:20122977.

Marshall, K. N., D. J. Cooper, and N. T. Hobbs. 2014. Interactions among herbivory, climate, topography and plant 
age shape riparian willow dynamics in northern Yellowstone National Park, USA. Journal of Ecology 102:667677.

Menard, C. B., R. Essery, and J. Pomeroy. 2014. Modelled sensitivity of the snow regime to topography, shrub fraction and shrub height. Hydrology and Earth System Sciences 18:23752392.

Myers-Smith, I. H., et al. 2011a. Shrub expansion in tundra ecosystems: dynamics, impacts and research priorities. Environmental Research Letters 6:045509.

Myers-Smith, I. H., et al. 2011b. Shrub expansion in tundra ecosystems: dynamics, impacts and research priorities. Environmental Research Letters 6:045509.

Myers-Smith, I. H., et al. 2015. Climate sensitivity of shrub growth across the tundra biome. Nature Climate Change $5: 887-891$.

Næss, M. W., and B. J. Bårdsen. 2010. Environmental stochasticity and long-term livestock viability-herd-accumulation as a risk reducing strategy. Human Ecology 38:3-17.

Normand, S., et al. 2013. A greener Greenland? Climatic potential and long-term constraints on future expansions of trees and shrubs. Philosophical Transactions of the Royal Society B 368:20120479.

Olofsson, J., L. Oksanen, T. Callaghan, P. E. Hulme, T. Oksanen, and O. Suominen. 2009. Herbivores inhibit climate-driven shrub expansion on the tundra. Global Change Biology 15:2681-2693.

Pajunen, A. M., E. M. Kaarlejarvi, B. C. Forbes, and R. Virtanen. 2010. Compositional differentiation, vegetation-environment relationships and classification of willow-characterised vegetation in the western Eurasian Arctic. Journal of Vegetation Science 21:107-119.

Pearson, R. G., S. J. Phillips, M. M. Loranty, P. S. A. Beck, T. Damoulas, S. J. Knight, and S. J. Goetz. 2013. Shifts in Arctic vegetation and associated feedbacks under climate change. Nature Climate Change 3:673-677.

Pellissier, L., et al. 2013. Thermal niches are more conserved at cold than warm limits in arctic-alpine plant species. Global Ecology and Biogeography 22:933-941.

Post, E., and C. Pedersen. 2008. Opposing plant community responses to warming with and without herbivores. Proceedings of the National Academy of Sciences USA 105:1235312358.

Post, E., et al. 2009. Ecological dynamics across the Arctic associated with recent climate change. Science 325:1355-1358.

R Core Team. 2013. R 3.0.2. R Foundation for Statistical Computing, Vienna, Austria. www.r-project.org

Ratajczak, Z., J. B. Nippert, and T. W. Ocheltree. 2014. Abrupt transition of mesic grassland to shrubland: evidence for thresholds, alternative attractors, and regime shifts. Ecology 95:2633-2645.

Ravolainen, V. T., N. G. Yoccoz, K. A. Brathen, R. A. Ims, M. Iversen, and V. T. Gonzalez. 2010. Additive partitioning of diversity reveals no scale-dependent impacts of large ungulates on the structure of tundra plant communities. Ecosystems 13:157-170.

Ravolainen, V., K. A. Bråthen, R. A. Ims, N. G. Yoccoz, and E. Soininen. 2013. Shrub patch configuration at the landscape scale is related to diversity of adjacent herbaceous vegetation. Plant Ecology and Diversity 6:257-268.

Ravolainen, V. T., K. A. Bråthen, N. G. Yoccoz, J. Nguyen, and R. A. Ims. 2014. Complementary impacts of small rodents and semi-domesticated ungulates limit tall shrub expansion in the tundra. Journal of Applied Ecology 51: 234-241.
Rich, M. E., L. Gough, and N. T. Boelman. 2013. Arctic arthropod assemblages in habitats of differing shrub dominance. Ecography 36:994-1003.

Roininen, H., T. Nyman, and A. G. Zinovjev. 2005. Biology, ecology, and evolution of gall-inducing sawflies (Hymenoptera: Tenthredinidae and Xyelidae). Pages 467-494 in A. Raman, C. W. Schaefer, and T. M. Withers, editors. Biology, ecology, and evolution of gallinducing arthropods. Science Publishers, Enfield, New Hampshire, USA.

Scheffer, M., and S. R. Carpenter. 2003. Catastrophic regime shifts in ecosystems: linking theory to observation. Trends in Ecology and Evolution 18:648-656.

Speed, J. D. M., G. Austrheim, A. J. Hester, and A. Mysterud. 2013. The response of alpine Salix shrubs to long-term browsing varies with elevation and herbivore density. Arctic, Antarctic, and Alpine Research 45:584-593.

Staver, A. C., and W. J. Bond. 2014. Is there a "browse trap"? Dynamics of herbivore impacts on trees and grasses in an African savanna. Journal of Ecology 102:595-602.

Sturm, M., C. Racine, and K. Tape. 2001. Climate changeincreasing shrub abundance in the Arctic. Nature 411: $546-547$.

Swanson, D. K. 2015. Environmental limits of tall shrubs in Alaska's Arctic national parks. PLoS ONE 10:e0138387.

Sweet, S. K., L. Gough, K. L. Griffin, and N. T. Boelman. 2014. Tall deciduous shrubs offset delayed start of growing season through rapid leaf development in the Alaskan Arctic tundra. Arctic Antarctic and Alpine Research 46: 682-697.

Tape, K., M. Sturm, and C. Racine. 2006. The evidence for shrub expansion in Northern Alaska and the Pan-Arctic. Global Change Biology 12:686-702.

Tape, K. D., M. Hallinger, J. M. Welker, and R. W. Ruess. 2012. Landscape heterogeneity of shrub expansion in Arctic Alaska. Ecosystems 15:711-724.

Tømmervik, H., B. Johansen, J. A. Riseth, S. R. Karlsen, B. Solberg, and K. A. Høgda. 2009. Above ground biomass changes in the mountain birch forests and mountain heaths of Finnmarksvidda, northern Norway, in the period 1957-2006. Forest Ecology and Management 257:244-257.

Tveraa, T., P. Fauchald, N. G. Yoccoz, R. A. Ims, R. Aanes, and K. A. Hogda. 2007. What regulate and limit reindeer populations in Norway? Oikos 116:706-715.

Tveraa, T., A. Stien, H. Brøseth, and N. G. Yoccoz. 2014. The role of predation and food limitation on claims for compensation, reindeer demography and population dynamics. Journal of Applied Ecology 51:1264-1272.

Väisänen, M., H. Ylänne, E. M. Kaarlejarvi, S. Sjögersten, J. Olofsson, N. Crout, and S. Stark. 2014. Consequences of warming on tundra carbon balance determined by reindeer grazing history. Nature Climate Change 4:384-388.

Vorren, Ø. 1962. Finnmarksamenes nomadisme. Universitetsforlaget, Oslo, Norway.

Vors, L. S., and M. S. Boyce. 2009. Global declines of caribou and reindeer. Global Change Biology 15:2626-2633.

van der Wal, R. 2006. Do herbivores cause habitat degradation or vegetation state transition? Evidence from the tundra. Oikos 114:177-186.

Walker, D. A. 2000. Hierarchical subdivision of Arctic tundra based on vegetation response to climate, parent material and topography. Global Change Biology 6:19-34.

Walker, D. A., et al. 2005. The circumpolar Arctic vegetation map. Journal of Vegetation Science 16:267-282. 
Williamson, S. N., I. C. Barrio, D. S. Hik, and J. A. Gamon. 2016. Phenology and species determine growing-season albedo increase at the altitudinal limit of shrub growth in the sub-Arctic. Global Change Biology. https://doi.org/10.1111/gcb.13297

Wolf, E. C., D. J. Cooper, and N. T. Hobbs. 2007. Hydrologic regime and herbivory stabilize an alternative state in
Yellowstone National Park. Ecological Applications 17: $1572-1587$

Wookey, P. A., et al. 2009. Ecosystem feedbacks and cascade processes: understanding their role in the responses of Arctic and alpine ecosystems to environmental change. Global Change Biology 15:1153-1172.

\section{SUPPORTING INFORMATION}

Additional supporting information may be found online at: http://onlinelibrary.wiley.com/doi/10.1002/eap.1618/full

\section{Data Availability}

Data available from the UiT Open Research Data Repository: https://doi.org/10.18710/saoag5. 